\title{
The Fields of Flow and Temperatures in the Chambers of Radiation of Tube Furnaces with Multi-tier Wall Burners of Two Types
}

\author{
Vafin Danil Bilalovich \\ Department of Electrical Engineering and Energy Supply of Enterprises, Faculty of Automation and Control, Institute of Chemical \\ Technology of Nizhneamsk (Branch) Kazan National Research Technological University, Kazan, Russian Federation

\section{Email address:} \\ vafdanil@yandex.ru

\section{To cite this article:} \\ Vafin Danil Bilalovich. The Fields of Flow and Temperatures in the Chambers of Radiation of Tube Furnaces with Multi-tier Wall Burners of \\ Two Types. International Journal of Fluid Mechanics \& Thermal Sciences. Vol. 5, No. 2, 2019, pp. 43-49. \\ doi: $10.11648 /$ j.ijfmts.20190502.12
}

Received: April 12, 2019; Accepted: May 23, 2019; Published: June 4, 2019

\begin{abstract}
In the article, the differential method of thermal calculation of a furnace is used to determine the aerodynamic and thermal characteristics in the chambers of radiation of tube furnaces with wall burners of two types located on several tiers. In the methane steam reforming furnace, the acoustic burners of the near-wall flame gas fuel are arranged in three tiers on the side walls of the radiation chamber. In the primary reforming furnace for the production of ammonium nitrate, wall-mounted burners are located on six tiers. The method implies joint numerical solution of 2D radiation transfer equations using the $S_{2}-$ approximation of the discrete ordinate method, of energy equations, flow equations, $k-\varepsilon$ turbulence model, and two stage modeling of gas fuel combustion. Is it given a brief description of the boundary conditions for differential equations and the method of their numerical solution. The results of the calculation of the temperature fields and the flow of combustion products in the radiation chamber of the furnace obtained with the help of a computer program that implements the described method are given.
\end{abstract}

Keywords: Thermal Radiation, Temperature, Heat and Mass Transfer, Combustion, Turbulence, Radiation Chamber

\section{Introduction}

The petroleum refinery industry and petrochemical industry operates with tube furnaces ensuring a short-term stay of combustion products; so a high heat intensity for long tubes should be provided in the furnace designing. The common practice is using of cup-shaped injection-type burners, or surface panel burners, or burners designed for near-wall flame; the latter version needs a multi-tier arrangement of burners on the lateral walls within the radiation section of a tube furnace. Recently, the market has offered the flat-flame gas burners of acoustic type (Acoustic Gas Burner, AGB) [1].

Figure 1 depicts a simplified view for a quadrant of the radiative chamber of tube furnace; it is equipped with AGBs arranged in three tiers on the lateral walls. A mixture of gaseous hydrocarbons and water steam are fed inside the vertical tubes (one raw) and the mixture is heated to the desired temperature due to radiation from combustion products and from hot wall of furnace (symmetric arrangement relative the tubular screen). The composite flame from many burners covers the lining in the circular shape and this creates a temperature field on the radiating walls.

In figure 2 shows a simplified diagram of the tubular furnace of the primary reforming of ammonium nitrate production, which is the main apparatus at the gas preparation stage and is designed to produce converted gas using the steam catalytic conversion of natural gas hydrocarbons. In the radiation chambers of the primary reforming furnace, 288 pieces are located, reaction tubes with a nickel-containing catalyst R-67R-7H / R-67-7H. The primary reforming furnace consists of two lined heated radiation chambers with a forced draft from the exhaust fan. Radiation chambers are equipped with wall horizontal burners (720 pieces in two chambers) without 
forced air supply. For milder conditions of heating the reforming furnace at start-up, the project provides for the installation of two types of burners of different power. Burners of the Walard WA4 type with a power of $266 \mathrm{~W}$ are located in the first tier of the burners (120 pcs., 30 pcs. On one side wall). Torches of type Walard WA5 with a power of $530 \mathrm{~W}$ are located in the remaining 5 tiers.

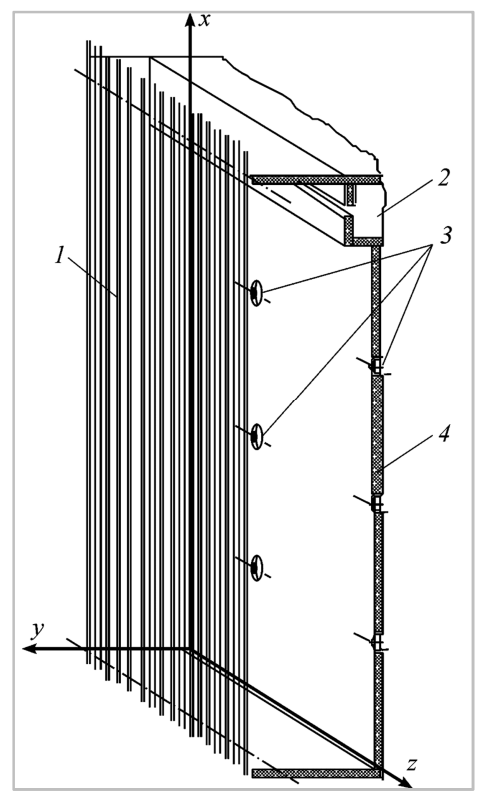

Figure 1. Diagram of a quadrant from the radiative chamber: 1 - tubular screen, 2 - path to the convection chamber, 3 - burners, 4-lined wall.

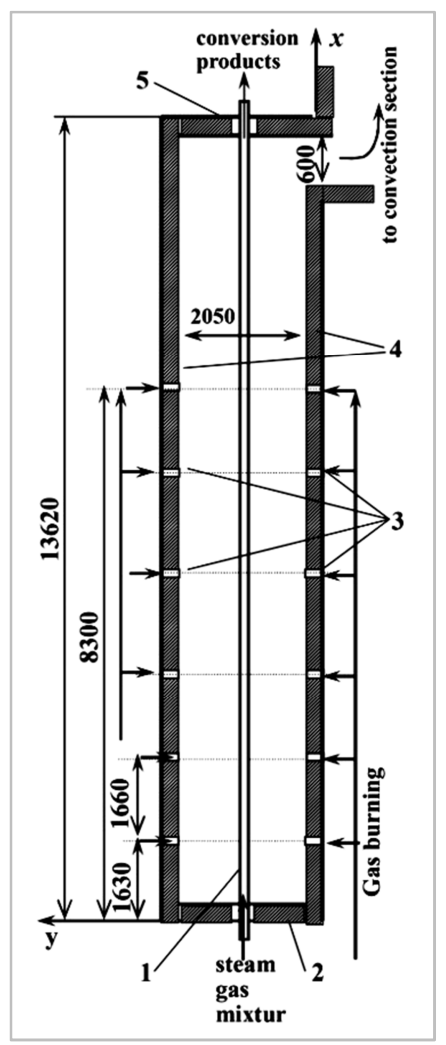

Figure 2. Cross section of radiation chamber: 1 - reaction tubes; 2 - under; 3 - burners; 4 - side walls; 5 - arch.
A review of simulation methods applied to fluid dynamics and heat and mass transfer is available in [2]. The current state of numerical methods for the study of the thermal radiation of combustion products was reviewed earlier [3]. A critical analysis of the publications dealing with energy transfer by radiation is available in the literature [4]. The methods for calculation of heat transfer in screened furnaces are classified into three groups: integral, zonal, and differential methods. The integral methods are based on similarity theory, including the technique of norm-calculation for tube furnaces [3]. This approach does not produce the local values for heat fluxes in the radiated surface, no locals for the lining temperature, or accounting of contribution from nonisothermal and optically non-uniform medium inside the furnace. When we deal with a zonal method of calculation, the inside space of furnace and the boundaries of emissive system are slit into several zones: each of selected zone has optical and thermal uniformity. All the mentioned approaches are a rough version of a differential scheme: it is simplified through using of empirical laws and parameters [5]. For example, the zonal method procedure (but without presenting of calculation results for the type of furnace described in the current paper) was outlined in [6]. In the zonal approach, the temperature field, coefficients of convectiveturbulent transfer between the selected zones are taken from the other fields of knowledge: simulations and experiments on fluid dynamics and convective heat transfer for tube furnaces. Recently, researchers start to apply new methods for thermal calculation of furnaces: they are based on joint numerical solution of radiative energy transfer and gas dynamics equations (all written in differential form). The paper [7] offered a general method for simulation of threedimensional furnace space with account for return flow combustion products, combustion, and combined heat transfer. In the article [8] presents the results of a numerical study of flow of an unsteady MHD free convection heat and mass transfer flow of a viscous, incompressible and electrically conducting fluid over an impulsively started infinite vertical plate in presence of thermal radiation. Heat radiation is taken into account in a simplified form in a gray approximation. A three-dimensional calculation of the heat transfer in the chamber of a technological tubular oven with the combustion of methane in air with acoustical burners of a floor flame has been carried in [9].

Today we have several market-available software packages like ANSYS FLUENT, CFX, Flow Vision, etc. We can also tell about a code packages like VP2/3 and $\sigma$-Flow [10]: they are adapted for simulation of a $3 \mathrm{D}$ flow with account for combustion of gaseous, liquid or pulverized fuel and with account for convective-radiative heat transfer.

\section{Mathematical Formulation}

As can be seen from Figures 1 and 2, the radiation chamber of the tube furnaces under consideration is almost symmetrical with respect to the tubular reactors. As a result, calculations can be performed for only half of the camera. 
The depth of the chamber along the $\mathrm{z}$ axis is $13-16 \mathrm{~m}$. Thus, the width of the radiation chamber section $1-1.3 \mathrm{~m}$ is much smaller than the height $(12-13.6 \mathrm{~m})$ and the depth of the radiation chamber, which allows us to consider the problem of complex heat and mass transfer in a two-dimensional formulation.

This method is based on concurrent integration of equations: 2D equations of radiative transfer within approximation of discrete ordinate method (1), energy equation (2), turbulent flow of a gas mixture (3), twoparametric $k-\varepsilon$ turbulence model (4), continuity equation and gas state (5), convective-diffusion equation for transfer of air and fuel components (6):

$$
\left.\begin{array}{c}
\mu_{\mathrm{m}} \frac{\partial I_{m}^{k}}{\partial x}+\xi_{\mathrm{m}} \frac{\partial I_{m}^{k}}{\partial y}=\alpha_{\mathrm{k}} \int_{\lambda_{k-1}}^{\lambda_{k}} I_{b \lambda} d \lambda-\left(\alpha_{\mathrm{k}}+\beta_{\mathrm{k}}\right) I_{m}^{k}+\frac{\beta_{k}}{4 \pi} \sum_{m^{\prime}=1}^{N_{o}} w_{m^{\prime}} \varphi_{m^{\prime} m} I_{m^{\prime}}^{k}, \\
\rho \mathrm{c}_{\mathrm{p}} \mathrm{u} \frac{\partial T}{\partial x}+\rho \mathrm{c}_{\mathrm{p}} v \frac{\partial T}{\partial y}=\frac{\partial}{\partial x}\left(\lambda_{e f} \frac{\partial T}{\partial x}\right)+\frac{\partial}{\partial y}\left(\lambda_{e f} \frac{\partial T}{\partial y}\right)+\left(\mathrm{q}_{\mathrm{v}}-\operatorname{divq}_{\mathrm{p}}\right), \\
\rho u \frac{\partial u}{\partial x}+\rho v \frac{\partial u}{\partial y}=-\frac{\partial p}{\partial x}+\frac{\partial}{\partial x}\left(\mu \operatorname{ef}\left(2 \frac{\partial u}{\partial x}-\frac{2}{3} \operatorname{div} \mathbf{v}\right)\right)+\frac{\partial}{\partial y}\left(\mu \mathrm{ef}\left(\frac{\partial u}{\partial y}+\frac{\partial v}{\partial x}\right)+f 1,\right. \\
\rho u \frac{\partial v}{\partial x}+\rho v \frac{\partial v}{\partial y}=-\frac{\partial p}{\partial y}+\frac{\partial}{\partial x}\left(\mu \operatorname{ef}\left(\frac{\partial u}{\partial y}+\frac{\partial v}{\partial x}\right)\right)+\frac{\partial}{\partial y}\left(\mu \mathrm{ef}\left(2 \frac{\partial v}{\partial y}-\frac{2}{3} \operatorname{div} \mathbf{v}\right)\right), \\
\frac{\partial}{\partial x}(\rho \mathrm{u} \phi)+\frac{\partial}{\partial y}(\rho v \phi)=\frac{\partial}{\partial x}\left(\Gamma_{\phi} \frac{\partial \varphi}{\partial x}\right)+\frac{\partial}{\partial y}\left(\Gamma_{\phi} \frac{\partial \varphi}{\partial y}\right)+\mathrm{S}_{\phi} \\
\frac{\partial(\rho u)}{\partial x}+\frac{\partial(\rho v)}{\partial y}=0, \mathrm{p}=\frac{\rho}{\mu_{\operatorname{mix}}} \mathrm{RT} .
\end{array}\right\}
$$

In those equations we use the following notations: $I_{m}^{k}$ is the radiation spectral emittance for selected directions $\mathbf{S}_{m}\{m$ $\left.=1, N_{0}\right\}$, and those vectors are assigned by a set of angular coordinates $\left\{\mu_{m}, \xi_{m}\right\} ; I_{b \lambda}(T)$ is the spectral emittance for a black body at temperature $T ; \alpha_{k}, \beta_{k}$ are the average spectral coefficients of absorption and scattering; $w_{m}$ are the weight coefficients [11]; $u, v$ are the components of velocity $\mathbf{v}$ for combustion products flow along axices $x$ and $y ; \rho$ is the density of combustion products; $c_{p}$ is the isobaric heat capacity; $\lambda_{\mathrm{ef}}=\lambda+\lambda_{\mathrm{t}}$ is the coefficient for effective thermal conductivity; $p$ is the pressure, $\mu_{\text {mix }}$ is the molar mass of the gas mixture; $R$ is the universal gas constant; $q_{v}$ is the volumetric density of heat sources; $\operatorname{div} \mathbf{q}_{\mathrm{p}}$ is the power of radiant flux density; $\mu_{\mathrm{ef}}=\mu+\mu_{\mathrm{t}}$ is the effective viscosity; the coefficients of turbulent viscosity and thermal conductivity calculated from formulas: $\mu_{\mathrm{t}}=c_{\mu} \cdot f_{\mu} \cdot \rho k^{2} / \varepsilon, \lambda_{\mathrm{t}}=c_{p} \mu_{\mathrm{t}} / \mathrm{Pr}_{\mathrm{t}}$; where $\operatorname{Pr}_{\mathrm{t}}$ is the turbulent Prandtl number; $f_{1}=-\rho g(1-\beta(T$ $\left.-T_{\infty}\right)$ is the mass force, where $\beta=(1 / \rho)(\partial \rho / \partial T)$ is the volumetric expansion coefficient; $g$ is the gravity acceleration; $T_{\infty}=290 \mathrm{~K}$ is the temperature taken as standard for calculation

$$
\mathrm{CH}_{4}+\alpha 3.99 \mathrm{O}_{2}+\alpha 5.96 \mathrm{~N}_{2}=2.744 \mathrm{CO}_{2}+2.246 \mathrm{H}_{2} \mathrm{O}+\alpha 5.96 \mathrm{~N}_{2}+(\alpha-1) \mathrm{O}_{2},
$$

where $\alpha$ is the air excess factor.

To calculate the spectral absorption coefficients of gases, it is necessary to know the distribution of the mole fractions of $\mathrm{H}_{2} \mathrm{O}, \mathrm{CO}_{2}$, and $\mathrm{CO}$ in the combustion chamber volume. the methane combustion model was used to determine them in two stages:

$$
\mathrm{CH}_{4}+1.5 \mathrm{O}_{2} \rightarrow \mathrm{CO}+2 \mathrm{H}_{2} \mathrm{O} \text { and } \mathrm{CO}+0.5 \mathrm{O}_{2} \rightarrow \mathrm{CO}_{2} \text {. }
$$

of buoyancy force; $\phi=\left\{k, \varepsilon, m_{\mathrm{CH}_{4}}, m_{\mathrm{CO}}, m_{\text {air }}\right\} ; k, \varepsilon$ is the kinetic energy of turbulent pulsations and kinetic energy dissipation rate; $S_{\phi}$ is a source term [12]; $\Gamma_{\phi}=\mu+\mu_{\mathrm{t}} / \sigma_{\phi}$ is the transfer coefficient in equation (4), $m_{\mathrm{CH}_{4}}$ and $m_{\mathrm{CO}}$ are the mass concentrations of methane and $\mathrm{CO} ; m_{\text {air }}$ are the mass concentrations of air; $S_{\mathrm{f}}=0,53 \rho g_{\mathrm{f}}^{1 / 2} \varepsilon / k$ is the rate of chemical reaction of combustion defined from "vortex break" model [13], $g_{\mathrm{i}}=2,27\left(\mu_{\mathrm{t}} k /(\rho \varepsilon)\left(\partial m_{\mathrm{i}} / \partial y\right)^{2}\right.$ is the rootmean-square pulsation component of fuel, $i=\mathrm{CH}_{4}, \mathrm{CO} ; \Gamma_{\phi}=$ $\mu / \sigma_{t}$ is the transfer coefficient in equation (4), where $\sigma_{t}$ is the Schmidt number. The constants for $k-\varepsilon$ model and expression for $f_{\mu}$ are taken according to recommendations [13]. Equation like (4) works also for $m_{\text {air }}$. The source term in the equation for the mass concentration of oxidizer (air) is found from relation $S_{\text {air }}=S_{\mathrm{f}} A$, where $A$ is stoichiometric air ratio for combustion of $1 \mathrm{~kg}$ of fuel $\left(\Gamma_{\mathrm{f}}=\Gamma_{\text {air }}\right)$.

In this paper, complete methane combustion is expected with the formation of $\mathrm{CO}_{2}$ and $\mathrm{H}_{2} \mathrm{O}, \mathrm{N}_{2}$, and $\mathrm{O}_{2}$ in final products (for example, for $1 \mathrm{~kg}$ of $\mathrm{CH}_{4}$ ):

Thus, the combustion model includes two equations of the (4) type for $m_{\mathrm{CH} 4}$ and $m_{\mathrm{CO}}$. In this case, the mass concentrations of the remaining components at the individual nodal points of the difference grid of the volume are determined by the mass concentrations of the fuel (methane) according to the stoichiometric coefficients of equations (6) and (7): 


$$
m_{\mathrm{CO}_{2}}=2.744 m_{\mathrm{CH}_{4}}^{\mathrm{cr}}, m_{\mathrm{H}_{2} \mathrm{O}}=2.246 m_{\mathrm{CH}_{4}}^{\mathrm{cr}}, m_{\mathrm{N}_{2}}=5.96 \alpha \rho g_{\mathrm{CH}_{4}}, m_{\mathrm{O}_{2}}=3.99 \alpha+(\alpha-1) \rho g_{\mathrm{CH}_{4}},
$$

where $m_{\mathrm{CH}_{4}}^{\mathrm{cr}}=\rho g_{\mathrm{CH}_{4}}$ is the concentration of burnt methane; $g_{\mathrm{CH}_{4}}=1 /(1+9.95 \alpha)$ is the mass fraction of methane in the initial mixture.

The flow in the tubular oven is subsonic, turbulent, and of a spatial character. The Reynolds number calculated in the width of the radiation section in the combustion region is $6 \cdot 10^{4}$. The features of specifying the boundary conditions for equations (1)-(5), the method of difference approximation of differential equations, and methods for numerically solving the system of algebraic equations obtained by an iterative method are described in detail elsewhere [2, 14].

In technical applications, the Edwards broadband model is often used to account for the selectivity of gas emissions, as in this paper. In this model, nine spectral bands are identified, with four bands corresponding to $\mathrm{H}_{2} \mathrm{O}$, two bands corresponding $\mathrm{CO}_{2}$, one band corresponding to the transparent spectral region, and two more bands that are due to overlapping of two pairs of bands: $2.7 \mu \mathrm{m}$ for $\mathrm{H}_{2} \mathrm{O}$ and $\mathrm{CO}_{2}, 10 \mu \mathrm{m}$ for $\mathrm{H}_{2} \mathrm{O}$, and $15 \mu \mathrm{m}$ for $\mathrm{CO}_{2}$. To reduce the number of bands of absorption, the Planck method of overlapping bands was used. As a result, the number of bands is reduced to six. A description of this model with reference to original works is given elsewhere [2].

The absorption coefficient at a given concentration is expressed in terms of the partial absorption coefficient $K_{p i}$

$$
\mathrm{a}_{\lambda \mathrm{i}}=\mathrm{K}_{\mathrm{pi}} \mathrm{p}_{\mathrm{i}}
$$

where $p_{i}$ is the partial pressure of the $i$ th component of the mixture $\left[K_{p i}\right]=(\mathrm{m} \cdot \mathrm{Pa})^{-1}$.

Since the content of soot particles is insignificant in the combustion products of gaseous fuels, their spectral absorption coefficient was calculated with the empirical formula [11]:

$$
\alpha_{s \lambda}=\frac{3 \pi}{2} \frac{\Phi(\lambda)}{\lambda} f_{v}
$$

where $\Phi(\lambda)$ is the function describing the dispersion of the optical constants of soot. In the spectral range up to $10 \mu \mathrm{m}$, the following formula can be used [15]:

$$
\Phi(\lambda)=1.75 /(1+0.3 \lambda) \text {. }
$$

The volume fraction of soot $f_{v}$ in (12) is determined by the empirical formula [16]:

$$
f_{v}=0.068(2-\alpha) C_{p} / H_{p}
$$

where the value of $C_{p} / H_{p}$ characterizes the relative weight of carbon in the working mass of the fuel [16]:

$$
C_{p} / H_{p}=0.12 \sum \frac{m}{n} C_{m} H_{n} .
$$

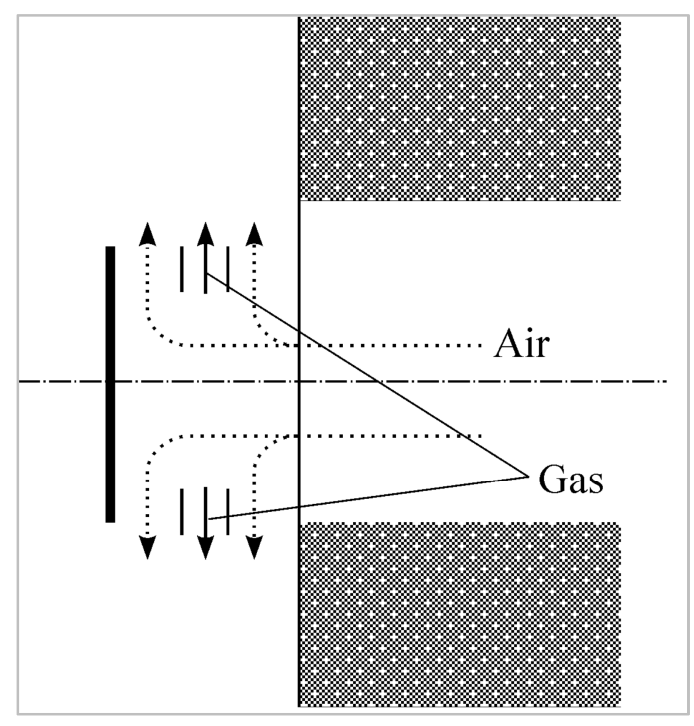

Figure 3. A diagram for burner modeling.

In modeling of acoustic burner operation, we assume that the gas (premixed with air) is fed to the radiation chamber through two narrow slots from opposite sides (see Figure 3). The secondary air is available from other four slots (two sides). Then the air-gas mixture is ignited, and combustion takes place near the wall.

The radiation chambers of the primary reforming furnace (Figure 2) are equipped with wall-mounted horizontal burners (360 pieces in one chamber) without forced air supply.

A simplified burner circuit is shown in figure $4 a$. A diagram of the simulation of the burner in two-dimensional calculations is shown in figure $4 b$. For milder conditions of heating the reforming furnace at start-up, the project provides for the installation of two types of burners of different power. Burners of the Walard WA4 type with a power of $266 \mathrm{~W}$ are located in the first tier of the burners (120 pcs., 30 pcs. on one side wall). Torches of type Walard WA5 with a power of $530 \mathrm{~W}$ are located in the remaining 5 tiers.

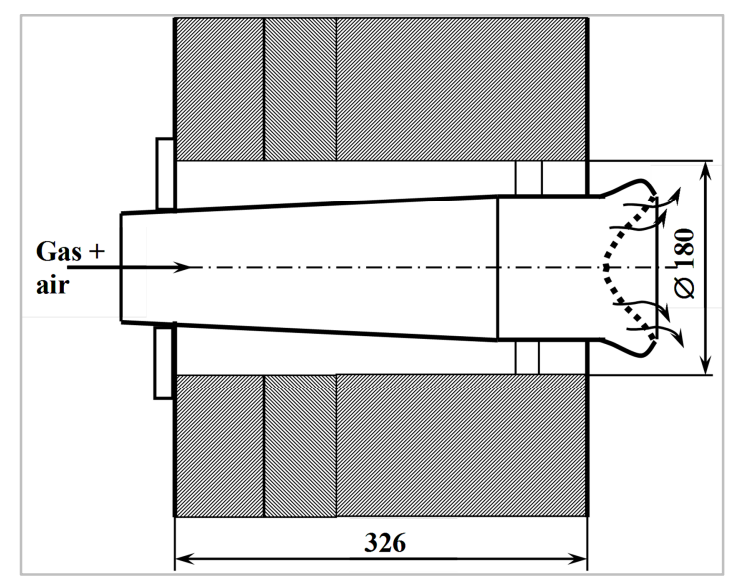

a 


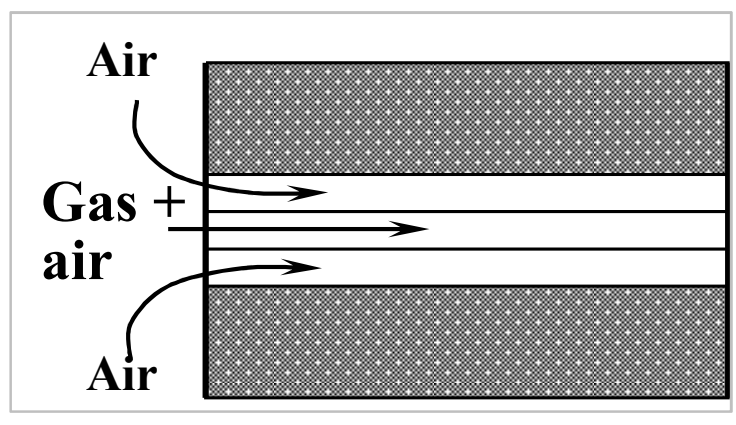

b

Figure 4. a) Simplified burner design WALARD; b) Burner modeling scheme.

A similar approach to the boundary conditions, numerical methods for equation solving, and testing of simulation versus experiment have been presented previously in $[2,14]$. The complex heat transfer problem is solved via an iteration scheme. For every iteration, the gas flow and heat transfer problems must be solved. However, the iterative process for joint solution of energy equation and transfer equation generates strong oscillations for temperature field and velocity field (for first external iterations). To suppress the "oscillation" magnitude, we used the under-relaxation approach and linearization of source terms in equations.

\section{Calculation Results}

The simulation of external heat transfer and flue gas aerodynamics for the case of near-wall combustion with using of acoustic-type nozzles was (figure 1) carried out for a configuration of a tube furnace with dual-side heating of the reaction-flow tubulars. In this type of furnace, the radiation chamber comprises two sections placed symmetrically relative to the one-row tubular coil (with vertical positioning of tubes). The number of tubes for a heated coil is 28 , their diameter is $134 \times 12 \mathrm{~mm}$, the coil pitch is $300 \mathrm{~mm}$, and the total length of tubes is $L=10 \mathrm{~m}$, the section width is $H=$ $1.5 \mathrm{~m}$. For simulated cases, the acoustic-atomizing burners were allocated in three tiers: the bottom tier is by $1.5 \mathrm{~m}$ above the hearth, and height interval between tiers is 2.5 $\mathrm{m}$. In our simulations, the fuel gas was methane. The gas flow rate for a half-chamber was $B_{\mathrm{f}}=0.198 \mathrm{~m}^{3} / \mathrm{s}$, the lower calorific value is $Q_{1}^{\mathrm{p}}==35818 \mathrm{~kJ} / \mathrm{m}^{3}$. The temperature of fuel at the nozzle inlet was $323 \mathrm{~K}$, and the inlet air has the same temperature. The excess-air factor is $\alpha_{\mathrm{t}}=1.07$. The gas fuel was distributed evenly to all burner of all tiers. The effective emissivity factor was 0.79 . The external surface of tubes has a temperature in the range from 1000 to $1200 \mathrm{~K}$. We assume that the solid surfaces have the diffusive mechanism for radiating of emission and reflecting the incident radiation. The emissivity factor for lateral lining was $\varepsilon=$ 0.42 , the thermal conductivity coefficient for multi-layered walls was $\lambda=0.35 \mathrm{~W} /(\mathrm{m} \cdot \mathrm{K})$. The thermal conductivity is the main mechanism of heat loss through the walls. The outside temperature of furnace was $300 \mathrm{~K}$. The wall thickness is 0.45 $\mathrm{m}$. The emissivity factor for ceiling was 0.67 , and for the furnace hearth it was 0.69 .

Figure 5 presents the change in temperature of the inside lining for a lateral wall as a function of chamber height. The outer temperature of the reactant-carrying tubes is also plotted. The temperature of lining is minimal near the burners: this zone is blown with gas-air mixture. The lining temperature increases in the zone of flame, and then it declines again as we depart away the nozzle tiers. In our simulation, the thermal conductivity takes place only across the wall. If one accounts for the heat transfer along the wall, the variation of temperature along $x$-axis would be smoother.

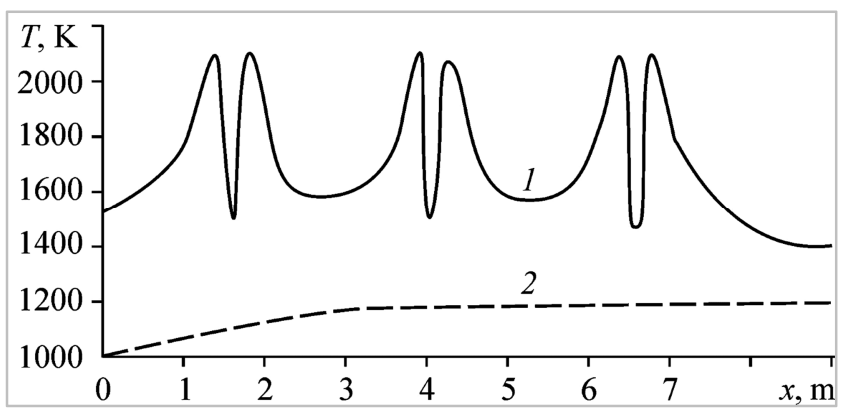

Figure 5. The variation of lining temperature and temperature of the external surface of tubes as a function of height in the radiation chamber: 1 - lining temperature, 2 - external temperature of the reactant-carrying tube.

Figure 6 shows the coordinate system and isotherms in the volume of the radiation chamber of the furnace with acoustic burners. For convenience, this plotting of isotherms was clockwise rotated by the angle of $90^{\circ}$ (in reality, the $x$-axis is directed upward, to the chamber ceiling). One can see that the top temperatures for combustion products take place near the lateral wall close to the fuel combustion area. The most of chamber volume is filled with combustion products; their temperature decreases gradually from $1500 \mathrm{~K}$ to $1420 \mathrm{~K}$ (near the tubular screen). The flue gas temperature declines as they flow to the convection section and becomes about $1270 \mathrm{~K}$ at the bridgewall: this fits the experimental data for furnace within accuracy $\pm 5 \mathrm{~K}$ (normal operational regime).

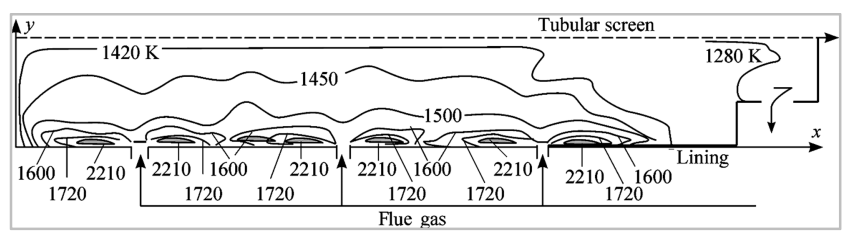

Figure 6. Coordinate system and isotherms within the radiation chamber.

Figure 7 shows isotherms of combustion products in a cross section of half of one radiation chamber of a primary reforming furnace (Figure 2) passing through the axes of the burners in the middle part of the chamber, obtained by calculation and the coordinate system. For convenience of location, the image is represented rotated $90^{\circ}$ and compressed in the direction of the $x$ axis.

Combustion of fuel gas, consisting mainly of methane, in the burners of the primary reforming furnace is performed with an excess air ratio $\alpha=1.1$, which is 
sucked from the atmosphere through the registers of the burner itself. The flue gas temperature at the outlet of each chamber of the radiant zone of the primary reforming furnace (the entrance to the convection zone) should be no more than $1060^{\circ} \mathrm{C}$ measured by the instrument 1-TIAH12025A and 1-TIAH-12025B. An alarm is provided in the central high-temperature control panel at $1075^{\circ} \mathrm{C}$ of flue gases.

Figure 8 shows the stream function $\psi$ for a single section of radiation chamber (figure 1). As was noted above, in the reality the $x$-axis is directed upward. The flow pattern has six zones of direct flow intermitted with recirculation flow zones. The first direct-flow zone is formed by flow of combustion products from the third tier of burner. These streamlines go along the upper part of lining of the lateral wall, then near the ceiling, and to the flue gas tunnel. For this layer, the temperature gradually decreases from $2210 \mathrm{~K}$ (combustion zone for the upper tier of burners) down to 1270 $\mathrm{K}$ (exit from the radiation chamber). The number six zone of direct flow originates from the combustion from bottom tier of burner: the flow moves toward the furnace sheath, then it goes along the tubes and reaches the bridgewall. For the second tier of burners, the flow pattern is different: the flue gases from the first tier and second tier are intermingled, and they join the flue gases of the first zone. The stream functions from the zones number four and five originate from the burners in the second and third tiers: the stream function line travels near the lateral wall (and heat up the lining) and later (above the second tier) joins the general direct flow.

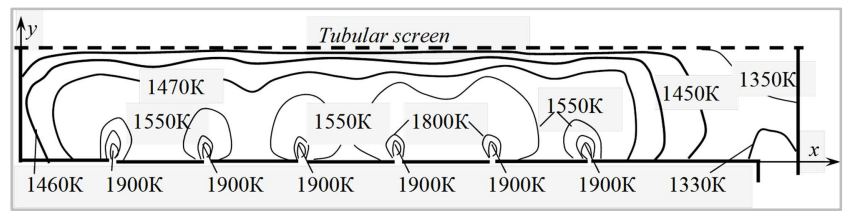

Figure 7. The temperature field at half the radiation chamber of the primary reforming furnace.

The recirculation zones happen in the furnace volume: they are detected near the tiers placement. The temperature of the recirculation flow is slightly lower $(1450 \mathrm{~K})$ : this is due to cooling action of the heating surface and to a remote position from the heat sources. The combustion products from the recirculation flow give inflow to the burner head, and this stabilizes the fuel mixture combustion.

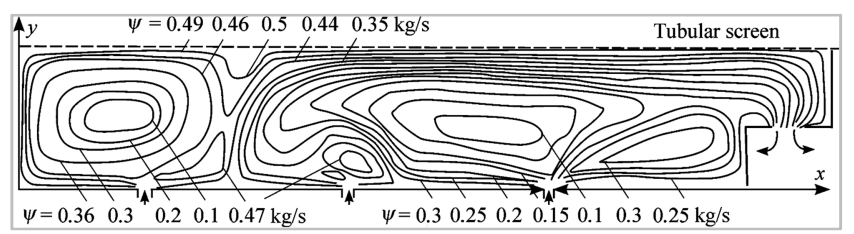

Figure 8. Streamlines pattern.

Figure 9 shows the lines of the function of the current in the radiation chamber of the primary reforming furnace (Figure 2).

\section{Conclusion}

1) These simulations demonstrate that the differential approach for calculation of furnaces is a good tool for identifying local temperatures and local velocities of combustion products inside the radiation chamber of a tube furnace (when the furnace is equipped with burners allocated in tiers).

2) The design thermal calculations of the furnaces considered are made on the assumption that the flue gas temperature is the same throughout the radiation chamber of $1200^{\circ} \mathrm{C}(1473 \mathrm{~K})$ and the same lining temperature of the side walls according to the integral method. As can be seen from Figures 4, 5, 6 and 7, the actual temperature field is very non-uniform. The estimated temperature level is obtained only closer to the tubular screen. At the same time, on the pass (transition to the convection section) the gas temperature corresponds to the design value.

3) Even with the use of a large number of wall burners, it is not possible to provide a uniform temperature field in the combustion chamber and a uniform distribution of heat fluxes along the reaction tubes. At the same time, when using acoustic burners located in three tiers, a more uniform temperature field is obtained near the reaction tubes than when using six longlines using horizontal wall burners. However, even in this case, the transfer of the required amount of heat to the reaction tubes for carrying out steam reforming of hydrocarbons and obtaining the required temperature of the reaction mixture at the outlet of the reaction tubes is ensured.

4) As calculations show, the maxima of temperature and heat flux are located at the level of the tiers of the burners. Therefore, in order to prevent local overheating of the pipes, it is necessary to control the uniform flow of fuel gas to the individual burner tiers and monitor the combustion mode. The correct burner flame should be blue with a yellow (straw) tip. In case the flame is yellow, the combustion does not occur completely and it is required to supply more air through the registers for combustion. Excess air will give the burner flame a clear blue color without a yellow tip.

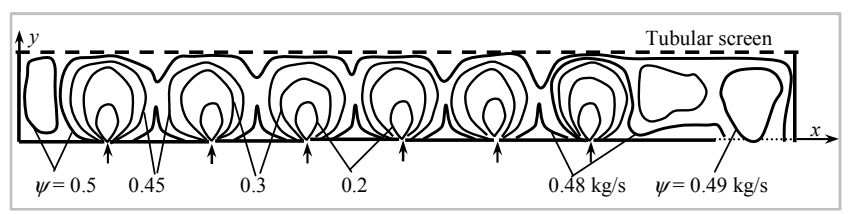

Figure 9. Streamlines pattern in the radiation chamber of the primary reforming furnace.

\section{References}

[1] Vafin D. B., Sadykov A. V. (2016). Thermal Calculation for a Furnace with Three-tiered Near-wall Burners. Thermophysics and Aeromechanics, 23 (2), 291 - 298. 
[2] Vafin D. B. (2011). Complex Heat Transfer / Radiative Heat Transfer in Power Plants, Saarbrücken, Deutschland: LAP LAMBERT Academic Publishing.

[3] Viskanta, R. (2005). Radiative Transfer in Combustion Systems: Fundamentals and Applications, New York: Begell House.

[4] Tencer, J. T. (2013). Error Analysis for Radiation Transport, Ph.D. Thesis, Austin, TX: Univ. Texas at Austin.

[5] Boiko E. A., Rovenskii D. P. (2009). A Dynamic Model for Simulating Fuel Combustion in the Flame of a Coal Fired Furnace. Izv. Vyssh. Uchebn. Zaved., Probl. Energ. (1-2)., 3-14.

[6] Kuleshov O. Yu., Sedelkin V. M. (2011). Calculation Technique for Conjugated Heat Transfer in Tube Furnaces Using a Zonal Approach. Izv. Vyssh. Uchebn. Zaved., Probl. Energ. (5-6). 47-54.

[7] Pai B. R., Michelfelder S, Spalding D. B. (1978) Prediction of Furnace Heat Transfer with a Three-dimensional Mathematical Model. Int. J. Heat Mass Transfer. 21 (5). 571-580.

[8] Kamalesh K. P., Sinam I. S., Dipak S. (2018). Heat and Mass Transfer Analysis of an Unsteady MHD Flow Past an Impulsively Started Vertical Plate in Presence of Thermal Radiaton. International Jornal of Fluid Mechanics \& Thermal Sciences. 4 (2). 18-26.

[9] Vafin D. B., Sadykov A. V., Butyakov M. A. (2018). Calculation of a Three-Dimensional Temperature Field with Allowance for the Radiation Heat Exchange in Chambers of Tubular Ovens with Acoustic Burners. High Temperature. 56 (4). $553-558$.
[10] Dektyarev A. A., Gavrilov A. A., Kharlamov E. B., Litvinets K, Yu. (2003). Use of $\sigma$-Flow Software for Simulation of Industrial Objects. Vychilsitelnye Tehnologii. 8 (1). 250-255.

[11] Fiveland W. A. (1995). Comparison of discrete-ordinates formulations for radiative heat transfer in multidimensional geometries. J. Thermophysics and Heat Transfer. 9. 47-53.

[12] Volkov K. N. (2005). Comparison of low-Reynolds number turbulence models with data of direct numerical simulation of channel flow. Thermophysics and Aeromechanics. 12 (3). 339-352.

[13] Spalding D. B. (1970). Mixing and chemical reaction in steady confined turbulent flames, 13th Inter. Symp. of Combustion: The Combustion Institute, Pittsburgh. 649-657.

[14] Vafin D. B., Sadykov A. V. (2018). Heat transfer in the furnaces of tube furnaces with burners of a flat flame. Mauritius: LAP LAMBERT Academic Publishing.

[15] Hubbard G. L. (1978). Infrared Mean Absorption Coefficients of Luminous Flames and Smoke. J. Heat Transfer. 100. 235.243.

[16] Blokh, A. G., (1984). Teploobmen v topkakh parovykh kotlov (Heat Exchange in Furnaces of Steam Boilers). Leningrad: Energoatomizdat. 